\title{
First report of Alternaria alternata causing leaf spots on Hibiscus syriacus in Italy
}

\author{
Angelo Garibaldi ${ }^{1} \cdot$ Giulia Tabone $^{1} \cdot$ Slavica Matić ${ }^{1} \cdot$ Incoronata Luongo ${ }^{2} \cdot$ Maria Lodovica Gullino $^{1}$
}

Received: 27 November 2019 / Accepted: 6 February 2020 / Published online: 17 February 2020

(C) Società Italiana di Patologia Vegetale (S.I.Pa.V.) 2020

Keywords Ornamental plants $\cdot$ Leaf spots

During the summer 2019, in a private garden near Biella (northern Italy), 50\% of 20 one-year-old plants of Hibiscus syriacus, Malvaceae family, showed brown leaf spots surrounded by a chlorotic halo. After a few days, a hole appeared on the center of the necrotic tissues. Pieces taken from the margins of the necrotic areas were plated on potato dextrose agar and olivaceous fungal colonies were isolated. A monoconidial culture grown on PDA produced dark-brown, ovoid or ellipsoid conidia characterized by 1 to 3 transverse, 0 to 2 longitudinal and 0 to 3 oblique septa. Conidia measured 12.1 to 42.2 (average $22.6) \times 4.9$ to 11.9 (average 8.6) $\mu \mathrm{m}(n=50)$, some of them showed a small light brown beak, measuring from 2.1 to $9.1 \mu \mathrm{m}$ (average 4.4). These morphological characteristics lead to identify the isolated fungus as Alternaria sp. (Simmons 2007). From the isolate coded $19 / 52$ we amplified ITS, $r p b 2$, endoPG and OPA 10-2 region (GenBank Accession Nos. MN654969; MN649031; MN649030; MN649032) (Woudenberg et al. 2015). BLASTn analysis showed $100 \%$ identity with the ex-type CBS 916.96 of Alternaria alternata in ITS, and rpb2 regions (AF347031, KC584375) and 99\% identity in OPA10-2 and endoPG portions (KP124632, JQ811978). Three pathogenicity tests were performed on unwounded leaves of three healthy plants of $H$. syriacus by

Giulia Tabone

giulia.tabone@unito.it

1 Centre of Competence for the Innovation in the Agro-Environmental Sector (AGROINNOVA), University of Torino, Largo Paolo Braccini 2, Grugliasco, 10095 Torino, Italy

2 Disafa, University of Torino, Largo Paolo Braccini 2, Grugliasco, 10095 Torino, Italy spraying conidial suspension at a concentration of $10^{5}$ conidia $/ \mathrm{ml}(5 \mathrm{ml} / \mathrm{plant})$. Three plants inoculated with deionized water served as control. Plants were covered with a plastic transparent bag for 5 days and maintained in a greenhouse at a temperature of $20-25^{\circ} \mathrm{C}$. After five days, leaf spots appeared on the inoculated plants and A. alternata was re-isolated, while the controls remained healthy. This pathogen is previously reported on H. syriacus (Farr and Rossman 2020) and this is the first report of A. alternata on H. syriacus in Italy and Europe.

\section{References}

Farr DF, Rossman AY (2020) Fungal Databases, U.S. National Fungus Collections, ARS, USDA. Retrieved February 4, 2020

Simmons EG (2007) Alternaria: an identification manual. CBS Biodiversity Centre, Utrecht

Woudenberg JHC, Seidl MF, Groenewald JZ, De Vries M, Stielow JB, Thomma BPHJ, Crous PW (2015) Alternaria section Alternaria: species, formae speciales or pathotypes? Stud Mycol 82:1

Publisher's note Springer Nature remains neutral with regard to jurisdictional claims in published maps and institutional affiliations. 